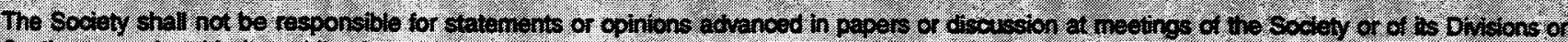

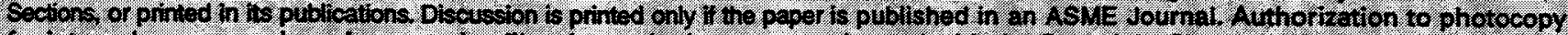

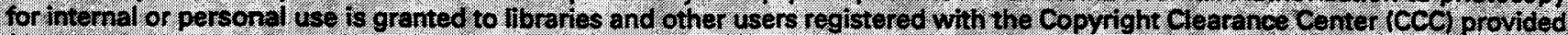

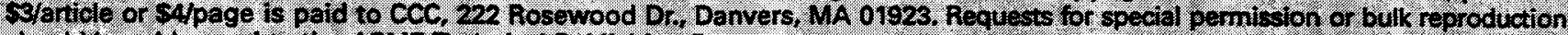
should be addressed to the ASME Teehnical Publishing Deparment.

\title{
DESIGN AND OFF-DESIGN ANALYSIS OF A CRGT CYCLE BASED ON THE LM2500-STIG GAS TURBINE
}

\author{
Carlo Carcasci, Bruno Facchini \\ DEF: Dipartimento di Energetica «S. Stecco» \\ University of Florence \\ via Santa Marta, 3 \\ 50139 Florence \\ ITALY \\ tel. (+39)-55-4796402/6235 - fax. (+39)-55-4796342 \\ e-mail: carca@brun.de.unifi.it , bruno@brun.de.unifi.it \\ Simon Harvey* \\ Dept. of Heat and Power Technology \\ Chalmers University of Technology \\ S-41296 Goteborg \\ SWEDEN \\ tel. (+46)-31772 8531 - fax (+46)-31821928 \\ e-mail: simon.harvey@hpt.chalmers.se
}

\begin{abstract}
Significant research effort is currently centered on developing advanced gas turbine systems for electric power generation applications. A number of innovative gas turbine cycles have been proposed lately, including the Humid Air Turbine (HAT), and the Chemically Recuperated Gas Turbine (CRGT). The potential of the CRGT cycle lies in the ability to generate power with a high efficiency while achieving ultra-low NO emissions without the need for selective catalytic reduction of the exhaust gases. Much of the research work published on the CRGT cycle is restricted to an analysis of the thermodynamic potential of the cycle. However, a detailed performance analysis of such cycles requires the development of a suitable cycle simulation code, capable of simulating cycle operation at the design point and in part load conditions. In this paper, the authors present a modular code for complex gas turbine cycle simulations. The code includes a module for design and off-design simulation of the methane-steam reformer chemical heat recovery device of a CRGT cycle. The code is then used to perform a detailed design and off-design performance analysis of a CRGT cycle based on the LM2500-STIG cycle adapted for chemical recuperation.
\end{abstract}

\section{NOMENCLATURE}

$\mathrm{d}=$ tube diameter

$\mathrm{m}=$ mass flow rate

$\mathrm{N}_{\mathrm{p}}=$ number of cold-side passes

$N_{r}=$ number of tube rows per pass
$\mathrm{p}_{\mathrm{L}}=$ longitudinal tube pitch
$\mathrm{p}_{\mathrm{T}}=$ transversal tube pitch
$\mathrm{P}=$ pressure
$\mathrm{T}=$ Temperature
$\mathrm{TIT}=$ First turbine stator inlet temperature
$\mathrm{V}_{\text {cat }}=$ catalytic volume
$\mathrm{W}=$ output power
$\mathrm{X}=$ mole
$\beta=$ pressure ratio
$\eta_{\text {th }}=$ thermodynamic efficiency
$\omega=$ shaft speed

[m]

[m]

\section{Subscripts and Superscripts}

$\begin{array}{ll}\mathrm{a}= & \text { air } \\ \mathrm{amb}= & \text { ambient } \\ \mathrm{APP} & =\text { approach } \\ \text { exh }= & \text { exhaust } \\ \mathrm{g}= & \text { hot gas } \\ \mathrm{hp}= & \text { high pressure } \\ \max = & \text { maximum } \\ \mathrm{Nom}= & \text { nominal } \\ \mathrm{PP}= & \text { pitch point } \\ \mathrm{I}= & \text { reforming gas } \\ \mathrm{s}= & \text { Steam }\end{array}$

"Previously at the Ecole de Mines de Nantes (France) - Dept. of Energy Systems Engineering (DSEE) 


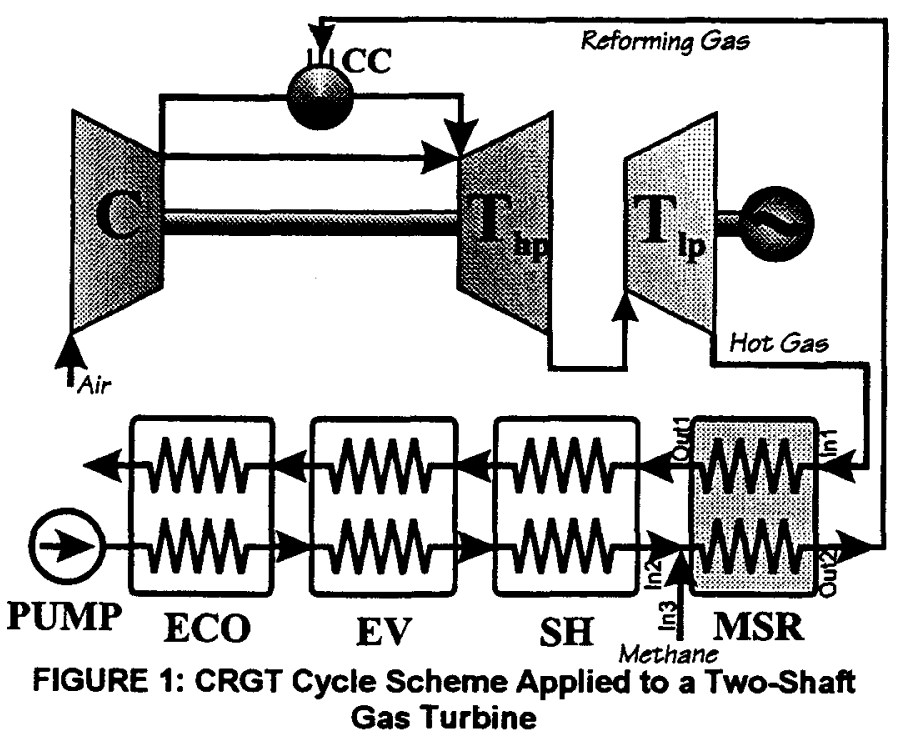

\section{INTRODUCTION}

Chemical recuperation is one of several innovative concepts applicable to natural gas fired gas turbine-based power generation cycles. Exhaust heat is recovered in a heat recovery steam generator (HRSG), where the superheater section is partially or totally replaced by a methane-steam reformer (MSR). The natural gas fuel is mixed with the generated steam and fed into the MSR. In the reformer, the mixture of natural gas and steam is heated by the combustion turbine exhaust, and an endothermic reaction occurs. The reaction requires the presence of a nickel-based catalyst, and results in the production of $\mathrm{H}_{2}, \mathrm{CO}_{2}$ and $\mathrm{CO}$. The methane/steam mixture therefore absorbs heat thermally (as the temperature increases), and chemically (as the endothermic reaction proceeds), resulting in a larger potential recuperation of exhaust energy than can be obtained by conventional recuperation. The reformed fuel is then fed into the turbine combustor. Thus, the CRGT cycle (figure 1) is similar to a STIG cycle, with additional heat recovery by chemical recuperation.

\section{Previous Work and Goal of Present Work}

The CRGT cycle has received relatively little attention from power generation cycle researchers compared to other innovative high performance gas turbine cycles. The CRGT cycle was considered by the CAGT Collaborative Advanced Gas Turbine program (Davidson et al., 1995). This program was initiated to promote R\&D programs for development of high performance gas turbine cycles for intermediate and base load applications, using state-of-the-art aeroderivative gas turbine technologies. However, in the screening phases of this program, only a few of the possible CRGT cycle configurations were considered. Furthermore, no results were presented for off-design performance, which is a key comparison criterion for future intermediate load high performance cycles. Along the same lines, Lloyd (1991) presented a detailed study of the thermodynamics of CRGT cycles, together with the results of a number of cycle simulations. Again, the results presented are only for

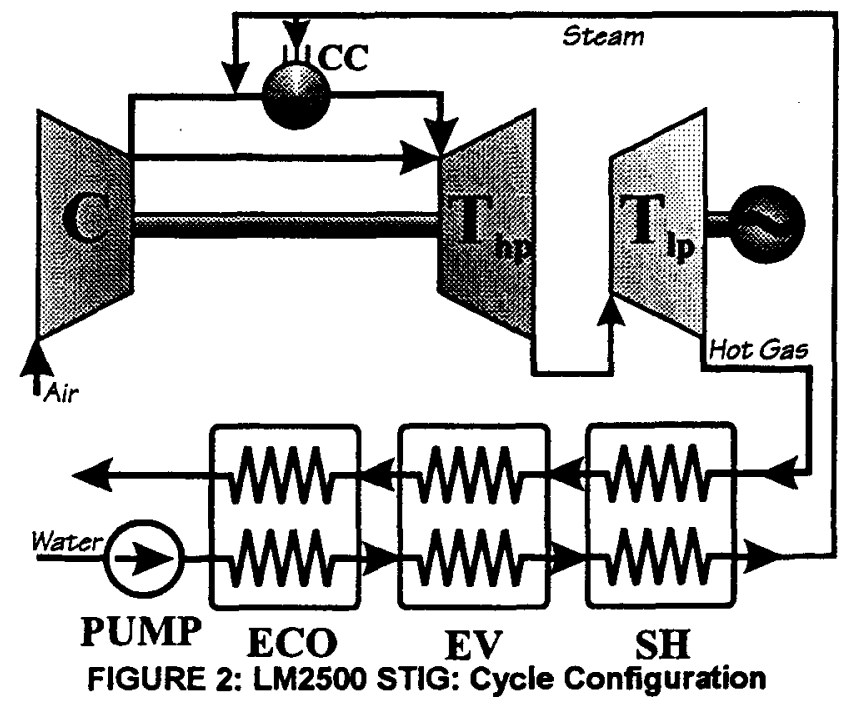

design-point operation, and no results are presented for part-load operation. Carcasci et al. (1997a) performed a thermodynamic analysis of a CRGT cycle based on an aeroderivative gas turbine (LM6000 gas turbine), and analyzed the performance potential of using reheat. A detailed study of the design of the Methane Steam Reformer (MSR) for a basic CRGT cycle was performed by Adelman et al. (1995) and by Carcasci and Harvey (1998).

Very few studies have been published in the field of off-design CRGT cycle performance. A recent study was published by Botros et al. (1997) discussing performance of a CRGT cycle used for mechanical drive application in pipeline compressor stations. This study includes some results of off-design performance calculations for an RB211 aeroderivative machine. However, this work assume that the design and off-design performance of the simple cycle RB211 are unaffected by the cycle modification implemented for CRGT operation.

In this paper we present results for off-design simulation of a CRGT cycle based on the LM2500 aeroderivative gas turbine. Using the already developed off-design approach for two-shaft gas turbine and HRSG-MSR, the study allows a complete off-design analysis considering the steam injection effects and MSR behavior with exhaust gas temperature and mass-flowrate variations.

\section{MODULAR CODE}

Given the complexity of the CRGT plant configurations, the proposed studies require the use of adequate calculation tools for plant simulation and performance predictions, with particular emphasis placed on partial load performance. The authors have used the modular code already developed by Carcasci and Facchini (1996); the reader is referred to previous papers (Carcasci and Facchini, 1996; Carcasci et al., 1996) for a complete presentation of the modular approach used.

A modular simulation code must be able to create a new power plant configuration, without creating a new source program. The code must also be able to handle any combination of input data. The modular code easily allows addition of new components (Carcasci and Facchini, 1996); thus subroutines for design and off-design simulations of the MSR can be added. 


\begin{tabular}{|c|c|c|c|c|c|}
\hline & \multicolumn{2}{|c|}{$\mathrm{LM} 2500 \mathrm{PE}^{(1)}$} & \multicolumn{2}{|c|}{$\begin{array}{l}\text { LM2500 PH } \\
\text { STIG }^{(2)}\end{array}$} \\
\hline & & GE & Code & $\overline{G E}$ & Code \\
\hline Output Power ${ }^{(3)}$ & kWe & 22800 & 22800 & 27400 & 27400 \\
\hline Heat Rate ${ }^{(3)}$ & $\mathrm{kJ} / \mathrm{kWeh}$ & 9785.6 & 9791.0 & 8894.1 & 8860.6 \\
\hline Thermod. efficiency & & 0.3754 & 0.3752 & 0.4130 & 0.4146 \\
\hline Shaft speed & $\mathrm{Hz}$ & 60 & 60. & 60 & 60. \\
\hline Exhaust Flow & $\mathrm{kg} / \mathrm{s}$ & 68.95 & 68.95 & 75.3 & 75.3 \\
\hline Exhaust Gas Temp. & $\mathrm{K}$ & 796.5 & 796.5 & 773.2 & 764.2 \\
\hline Pressure Ratio & & 18.8 & 18.8 & 20.2 & 20.1 \\
\hline Steam mass flow rate & $\mathrm{kg} / \mathrm{s}$ & $\overline{-}$ & $\overline{-}$ & 6.3 & 6.3 \\
\hline Steam Temperature & $\mathrm{K}$ & $\overline{-}$ & $\overline{-}$ & 588.7 & 588.7 \\
\hline Steam Pressure & $\overline{\mathrm{kPa}}$ & - & $\overline{-}$ & 2757.9 & 2757.9 \\
\hline
\end{tabular}

(1) Rating are at $15^{\circ} \mathrm{C}$, sea level, no inlet or exhaust losses and natural gas

(2) Rating are at $15^{\circ} \mathrm{C}$, sea level, $4^{\prime \prime} / 10^{\prime \prime}$ inlet/exhaust losses and natural gas

(3) At generator terminals

TABLE 1: LM2500 and LM2500-STIG Performance (GE Marine \& Industrial Engines, 1992) Compared with Code Results

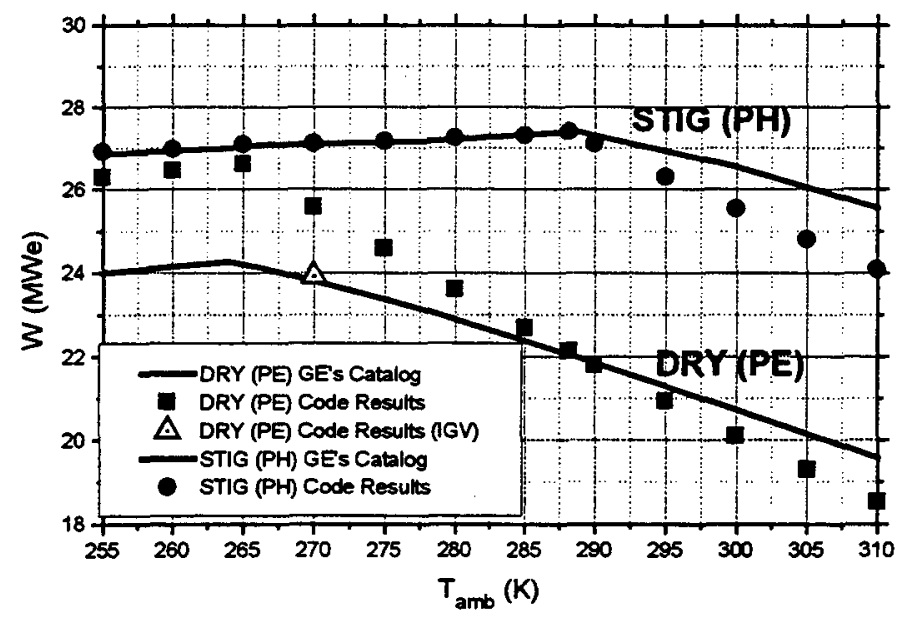

FIGURE 3: Power Output vs. Ambient Temperature. Code Results and Constructor Curves

The power plant configuration is defined by connecting a number of elementary components representing different unit operations such as compressors, pumps, combustion chambers, splitters, mixers, etc. Thus each component is defined as a black box capable of simulating a given chemical and thermodynamic transformation. All equations defining the power plant are linearized (the coefficients are however updated in the course of the calculation), so the code reduces the nonlinear equation system to a linear system with variable coefficients then all equations are solved simultaneously using a classic matrix method, so the procedure is essentially that of the fully implicit linear approach. With this approach, none of the data describing the different components of the system is considered essential, unlike a number of other semi-parallel or sequential methods.

\section{Design and Off-Design Analysis}

Partial load simulations with a modular approach have already

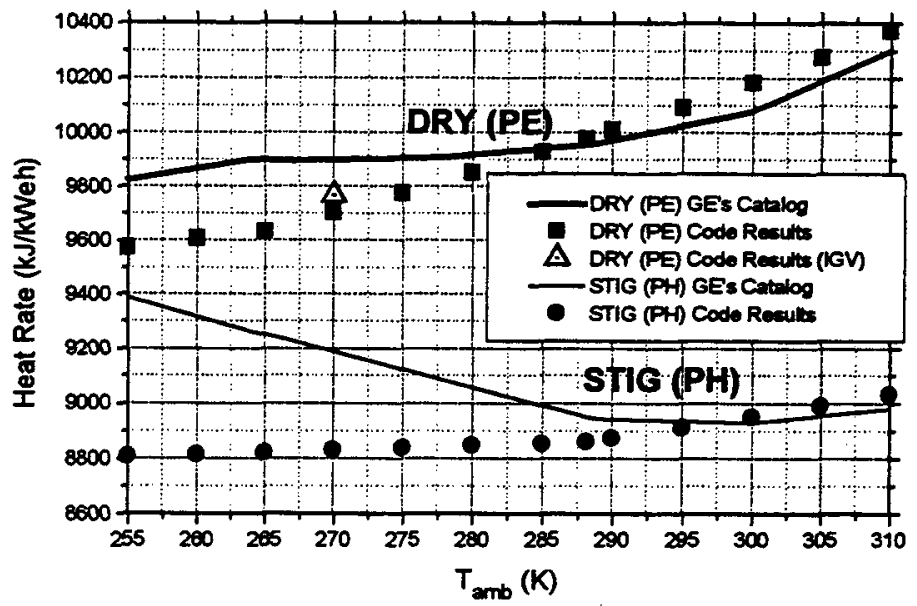

FIGURE 4: Heat Rate vs. Ambient Temperature. Code Results and Constructor Curves

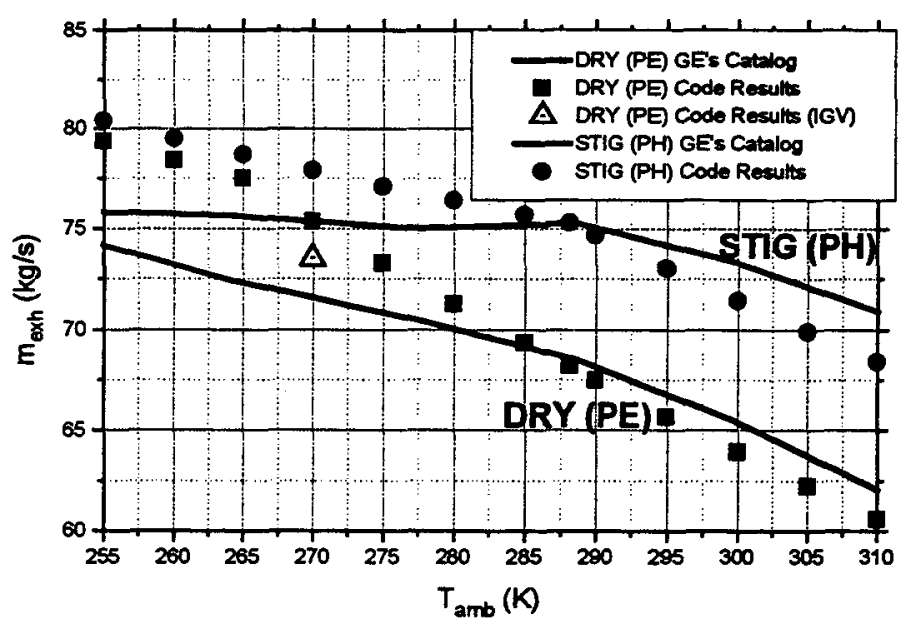

FIGURE 5: Exhaust Mass Flow Rate of Low Pressure Turbine vs. Ambient Temperature. Code Results and Constructor Curves

been proposed by some authors (Perz et al., 1995; Erbes et al., 1989) and they are based on the use of characteristic curves furnished by the equipment manufacturer. This information is inadequate for studying new cycles for which characteristic curves are not available. The method used in this study allows simplified component simulation resulting in a better description of cycle behavior and a better understanding of manufacturer provided information.

For off-design performance evaluation, the unit description becomes more complex and it requires a more detailed design approach. The design study requires a geometric description of the component (Facchini, 1993; Carcasci et al. 1996), which allows the characteristic parameters to be identified which can then be used in typical off-design correlations (e.g., the velocity triangle at mean radius and other cascade parameters for the compressor or turbine). For this parameter identification, the knowledge of some of the constructor's data can be important to improve simulation results. Thus the off-design study is based on fixed geometry (obtained by the 
design study), and there is a reduction in the number of input data.

The cycle component models other than the MSR are already discussed in previous papers (Carcasci et al., 1996; Bettagli and Facchini, 1995; Cumpsty, 1989; Facchini, 1993).

\section{MSR Model Description}

A new modular code component was developed to simulate the MSR in design and off-design configurations.

The key new component model defined in the course of this study is the Methane-Steam Reformer (MSR) model (see particular in figure 1). The turbine exhaust gas enters by input DN1, and is cooled as heat is transferred to the cold side of the reactor, in which the endothermic methane steam reforming reactions occur. The cooled exhaust gas leaves the MSR by output node OUT1. On the cold side, steam and methane enter the component separately by input nodes IN2 and IN3, respectively. The mixing of the two streams occurs within the component. The mix then enters the reaction zone, and the reformed gas stream leaves the component by exit node OUT2.

For thermodynamic analysis of the MSR, a simplified approach based on an energy balance and the chemical approach to equilibrium concept is sufficient (Carcasci et al., 1997a; Carcasci et al., 1997b). However, for design and off-design calculations, a more extended model must be developed.

In the present model, the MSR flow configuration used is that discussed by Carcasci and Harvey (1998): i.e. a heat recovery device similar to that of a traditional HRSG (counter-cross flow configuration). The general case with more than one row of tubes per cold-side pass is considered. The MSR is modeled by dividing it into control volumes. The equations used in a control volume of the MSR are chemical species balances, heat transfer equation, mass balances and enthalpy balances, as discussed in detail by Carcasci and Harvey (1998).

\section{LM2500 GAS TURBINE}

A CRGT power plant has similar mass flow characteristics to a STIG cycle plant. Thus in this study, we present results for a CRGT cycle based on the commercially available LM2500-STIG aeroderivative steam injected gas turbine.

The LM2500 industrial gas turbine is General Electric's most proven aeroderivative engine. It is derived from the TF-39 flight engine and many LM2500s are now in land and marine service.

The LM2500 consists of a twin-shaft engine (single rotor gas generator unit with a power turbine). The compressor is a 16-stage, axial flow design with inlet guide vanes and the first six stator with variable area vanes. The combustion chamber is of the annular type. A two stage, high pressure turbine drives the compressor, both stages of nozzle and turbine blades are air-cooled. The six stage, high efficiency power turbine is designed with a nominal speed of $3600 \mathrm{rpm}(60 \mathrm{~Hz})$ but can also be used in $50 \mathrm{~Hz}$ service (Smith, 1991). Table l shows some operating characteristic for the LM2500 dry cycle and STIG cycle machines.

In the STIG (STeam-Injected Gas) cycle, steam is typically produced in a heat recovery steam generator (HRSG) and is then injected into the gas turbine (figure 2). The additional mass flow that can be expanded in the standard LM2500 PE gas turbine is limited. Thus, GE has introduced a second model: the LM2500 PH which is the same as the PE version, except that the high pressure turbine inlet area has been slightly increased and the power turbine inlet area

\begin{tabular}{|c|c|c|}
\hline & & Value \\
\hline Width & $\mathrm{m}$ & 6.0 \\
\hline Height & $\mathbf{m}$ & 6.0 \\
\hline Tube outer diameter (d) & $\mathbf{m m}$ & 76.2 \\
\hline Trans. tube pitch $\quad\left(\mathrm{p}_{\mathrm{T}} / \mathrm{d}\right)$ & & 1.5 \\
\hline Long. row pitch $\quad\left(\mathrm{p}_{\mathrm{l}} / \mathrm{d}\right)$ & & 1.5 \\
\hline Tube arrangement & & Staggered \\
\hline Fin thickness & & 0.02 \\
\hline Fin height & & 0.20 \\
\hline Fin spacing & & 0.20 \\
\hline number of passes & & $8 / 10$ \\
\hline number of row each passes & & $3 / 4$ \\
\hline
\end{tabular}

TABLE 2: MSR Geometric Characteristic

slightly decreased, so it is able to accommodate higher amounts of steam and provide better performance in STIG operation (Smith, 1991). Data is also listed for this machine in Table 1.

The modular code allows the user to determine the characteristic parameters of a commercial gas turbine based on the manufacturer's published performance data.

The simulation of the LM2500 proceeds as follows:

1. Design simulation of LM2500 PE: the characteristic parameters of each component are determined at $15^{\circ} \mathrm{C}$, sea level, no inlet or exhaust losses, imposing the data shown in table 1. Using a few known operating characteristics (compression ratio, turbine outlet temperature and mass flow rate, gross efficiency, power, ambient conditions, shaft configuration, number of compressor and turbines stages), some general design parameters (i.e., flow coefficient, load coefficient, degree of reaction, stage loss coefficients) can be determined. LM2500 dry cycle simulation shows good agreement with the manufacturers performance data (GE Marine \& Industrial Engines, 1992. See table 1); the maximum error is of $0.06 \%$. The offdesign performance of the dry cycle, varying ambient temperature, is compared with the catalogue curve (figures 3,4 and 5). Good agreement is achieved in the right-hand zone, using a constant turbine inlet temperature TIT (first turbine stator inlet temperature). However, for low compressor inlet temperatures (left-hand zone), a reduction in turbine inlet temperature is imposed to avoid compressor surge, resulting in a lower compressor speed (free shaft). For ambient temperatures, the agreement between simulation and published manufacturer's data is not very good. This is because the simulation results are obtained without changing the IGV (Inlet Guide Vane) setting compared to the nominal ambient temperature point. The figures show that when the IGV setting is modified, better agreement can be found, as illustrated for operation at $270 \mathrm{~K}$ ambient temperature.

2. LM2500 PH STIG design simulation: steam is injected into the gas turbine, the resulting performance characteristics are compared with published performance data at nominal conditions. LM2500 STIG cycle simulation shows good agreement with manufactures performance data (GE Marine \& Industrial Engines, 1992. See table 1). The maximum error is of $1.2 \%$ for the computed heat rate. The simulation is performed varying the inlet area of the high pressure and low pressure turbines and running other components in off-design mode. A lower turbine inlet temperature is introduced to avoid choked flow in the turbine.

3. LM2500 PH STIG off-design simulation: the off-design performance of the STIG cycle, varying ambient temperature, is 


\begin{tabular}{|c|c|c|c|c|c|c|}
\hline $\mathrm{N}_{\mathrm{p}}$ & & 8 & 10 & 10 & 8 & 8 \\
\hline $\mathrm{N}_{\mathrm{t}}$ & & 4 & 3 & 4 & 5 & 3 \\
\hline$m_{a}$ & $\mathrm{~kg} / \mathrm{s}$ & 67.94 & 67.94 & 67.91 & 67.91 & 67.96 \\
\hline$\omega_{\text {hp }}$ & $\mathrm{rad} / \mathrm{s}$ & 843.3 & 843.4 & 843.2 & 843.2 & 843.5 \\
\hline$\beta$ & & 19.80 & 19.80 & 19.79 & 19.79 & 19.81 \\
\hline$T_{\max }$ & $\mathrm{K}$ & 1446.2 & 1446.2 & 1446.2 & 1446.2 & 1446.2 \\
\hline W & MW & 27.94 & 27.95 & 27.88 & 27.88 & 28.00 \\
\hline$\eta_{\text {th }}$ & & 0.4573 & 0.4573 & 0.4569 & 0.4568 & 0.4576 \\
\hline$m_{\text {exh }}$ & $\mathrm{kg} / \mathrm{s}$ & 75.45 & 75.45 & 75.41 & 75.41 & 75.48 \\
\hline$T_{\text {exh }}$ & $\mathrm{K}$ & 762.9 & 762.8 & 763.4 & 763.5 & 762.4 \\
\hline$m_{s}$ & $\mathrm{~kg} / \mathrm{s}$ & 6.291 & 6.291 & 6.281 & 6.280 & 6.298 \\
\hline$\Delta T_{p p}$ & $\mathrm{~K}$ & 49.8 & 44.9 & 47.7 & 51.1 & 48.4 \\
\hline $1+\mathrm{X}_{\text {and }}, \mathrm{X}_{\text {ansin }}$ & $\%$ & 12.57 & 12.10 & 13.73 & 13.85 & 10.87 \\
\hline $\begin{array}{l}\text { conversion } \\
\text { efficiency }\end{array}$ & $\%$ & 3.22 & 3.69 & 2.30 & 2.19 & 4.75 \\
\hline$\Delta \mathrm{T}_{\text {APP }}$ & $\mathrm{K}$ & 3.18 & 3.16 & 2.26 & 2.47 & 4.09 \\
\hline $\mathrm{P}_{\mathrm{exh}}$ & $\mathrm{kPa}$ & 103.9 & 103.8 & 104.2 & 104.2 & 103.6 \\
\hline$\Delta \mathrm{P}_{\mathrm{g}}$ & $\%$ & 1.23 & 1.16 & 1.50 & 1.54 & 0.93 \\
\hline$\Delta \mathrm{P}_{\mathrm{T}}$ & $\%$ & 19.52 & 32.61 & 22.93 & 13.98 & 28.51 \\
\hline $\mathrm{X}_{\mathrm{H} 2 \mathrm{O}} / \mathrm{X}_{\mathrm{CH} 4}$ & & 4.586 & 4.586 & 4.586 & 4.586 & 4.586 \\
\hline $\mathrm{V}_{\mathrm{cat}}$ & $\mathrm{m}^{3}$ & 36.88 & 34.57 & 46.10 & 46.10 & 27.66 \\
\hline
\end{tabular}

TABLE 3: Comparison between Various MSR Configurations

compared with catalogue performance curves (figures 3,4 and 5). The LM2500 PH STIG gas turbine has a pronounced compressor instability. Thus, to avoid surge, when the ambient temperature decreases (left-hand zone), a reduction of turbine inlet temperature (TIT) is necessary. In the present simulation, TIT is fixed so that power output is equal to constructor data. In these simulations the IGV setting is kept constant.

\section{SIMULATION OF LM2500-CRGT}

\section{CRGT Cycle Description}

The CRGT cycle is already described in previous sections. We assume that the steam is superheated before entering the MSR, since catalytic activity is very low below $600-650 \mathrm{~K}$

An important parameter is the combustor fuel port pressure loss. For fuel flow control reasons, the pressure drop through the fuel inlet port is usually high in gas turbines, on the order of $40 \%$ or higher. Such a high pressure drop e has a very negative impact on cycle performance for a CRGT cycle. The fuel port pressure drop is thus reduced to its minimum (full open) value, on the order of $10 \%$ (Larson and Hughes, 1996).

The molar steam-to-methane ratio in the reformer is usually between 3 and 6 in CRGT cycle typical applications, as discussed by Carcasci et al. (1997).

The same STIG operating conditions (i.e. steam mass flowrate and TIT) are imposed.

\section{MSR Design}

Design of the methane steam reformer heat recovery device

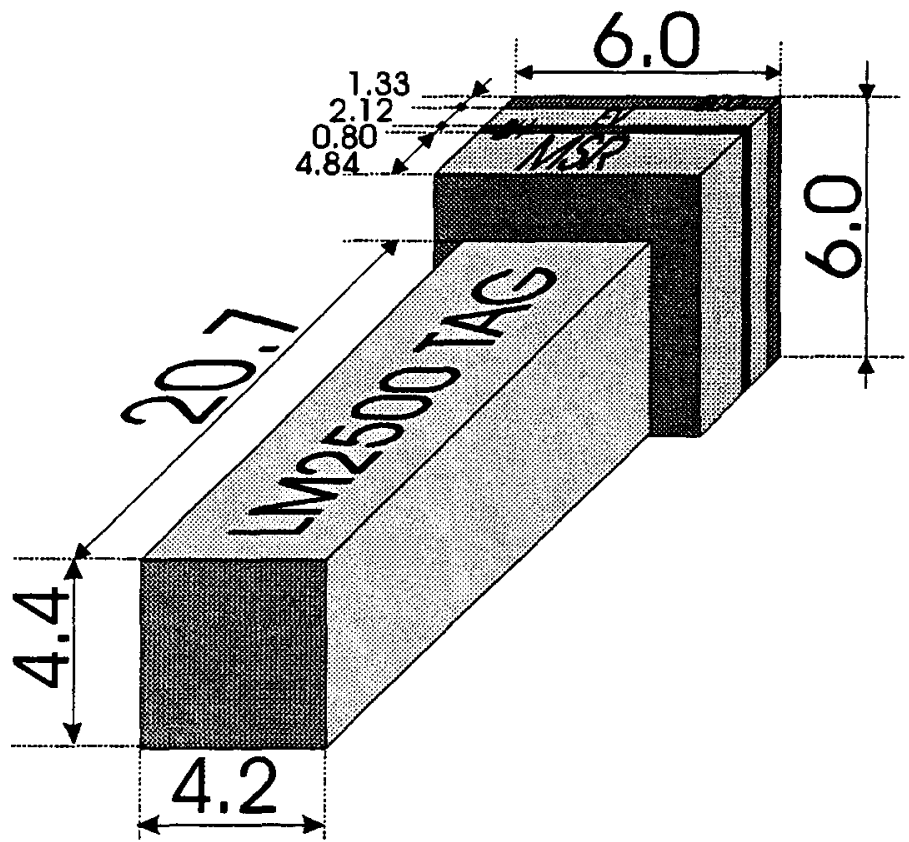

FIGURE 6: Dimension Comparison between LM2500 Gas Turbine, MSR and HRSG

involves a somewhat complex trade-off. The geometry selected should not only favor heat exchange, but also allow a sufficient residence time of the reforming gas in the MSR, so that the endothermic reaction can come close to chemical equilibrium. Furthermore, hot side and cold side pressure drops should be as low as possible: the former to decrease the latter pressure of gas turbine and the other to decrease the power absorbed by the pump and also to favor methane conversion (methane conversion at equilibrium is favored by low pressure). Finally the MSR dimension should be reasonable compared to those of the steam generator and the gas turbine.

In a companion paper, Carcasci and Harvey (1998) discuss various MSR design options, and they propose some MSR configurations of interest for a chemically recuperated LM2500 gas turbine. Table 3 shows all MSR geometric parameters fixed in the present simulation, as proposed by Carcasci and Harvey (1998).

Imposing the turbine inlet temperature and the steam mass flow rate, the steam-methane ratio in the MSR is thus fixed at $\mathrm{X}_{\mathrm{H} 2 \mathrm{O}} / \mathrm{X}_{\mathrm{CH} 4}=4.586$ for all MSR configurations considered.

Table 3 shows the most important operating characteristics of several MSR configurations. All MSR configurations show similar results. The best geometry is a MSR with 8 cold-side passes and 3 tube rows per pass (8/3). With this configuration, the methane conversion is the lowest, but the MSR hot gas pressure drop is also the lowest. This configuration is characterized by a strong reduction of catalytic volume (and thus low capital costs) and only a small reduction of power output (power depends mostly on steam mass flow rate) and of thermodynamic efficiency is observed.

Figure 6 gives an idea of physical dimensions of the power plant. The MSR component is longer than the HRSG, but its dimensions are reasonable ( 4.84 meters in length compared to 4.25 meters overall for the HRSG). 


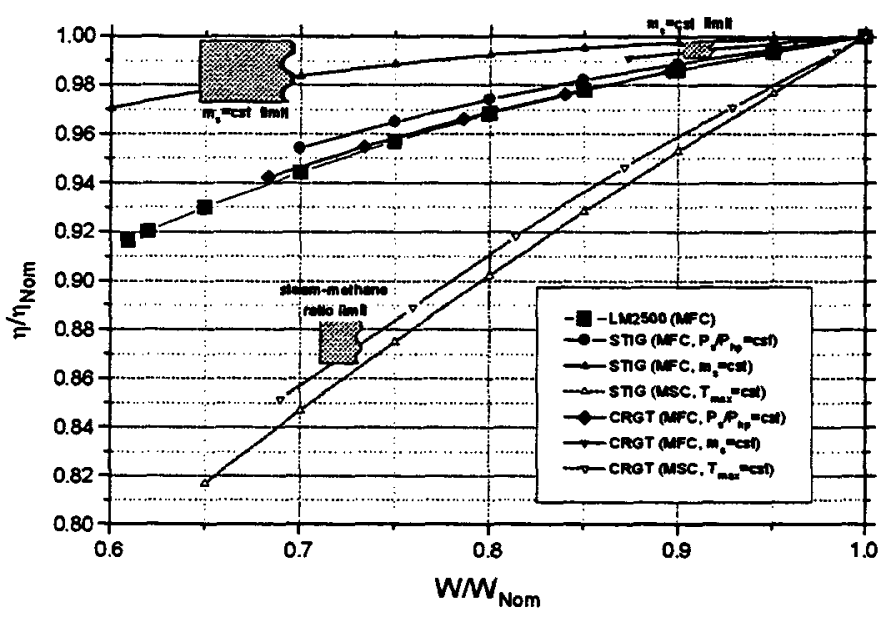

FIGURE 7: Thermodynamic Efficiency vs. Output Power. LM2500, LM2500 STIG and LM2500 CRGT

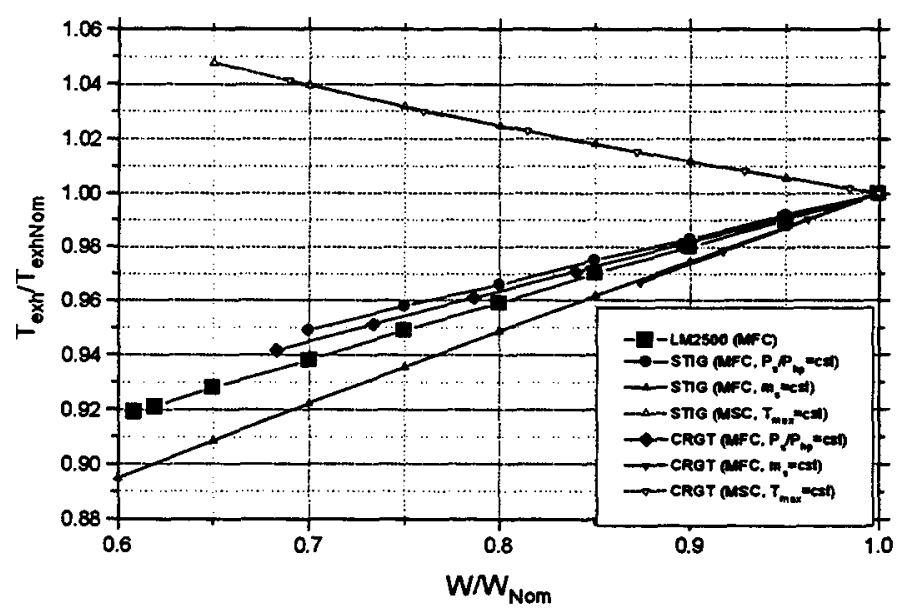

FIGURE 8: Exhaust Temperature of Low Pressure Turbine vs. Output Power. LM2500, LM2500 STIG and LM2500 CRGT

\section{OFF-DESIGN ANALYSIS}

In this paragraph, results for LM2500 CRGT off-design performance are shown and compared with LM2500 Dry and LM2500 STIG off-design performance values. All results are presented as relative values, compared to the nominal design point value.

\section{Partial Load Criteria}

When simulating a HRSG in off-design operation, only hot gas inlet conditions (i.e., mass flow rate and temperature), water inlet temperature (generally fixed by ambient conditions) and either steam pressure or steam mass flow rate can be fixed. Thus, if we impose the maximum temperature at which the steam can be re-injected into the gas turbine, the corresponding HRSG hot gas inlet conditions are determined. If all steam produced by the HRSG is re-injected into the

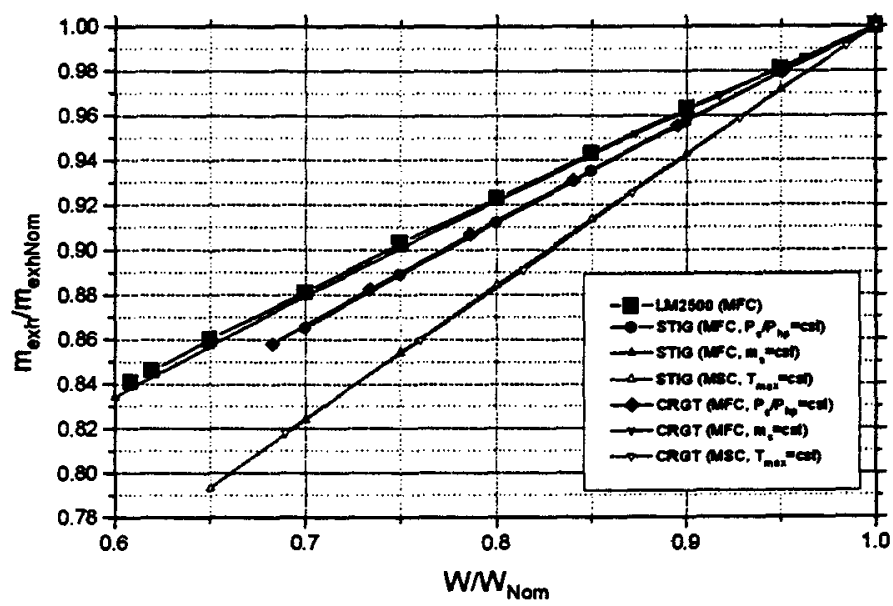

FIGURE 9: Exhaust Mass Flow Rate vs. Output Power. LM2500, LM2500 STIG and LM2500 CRGT

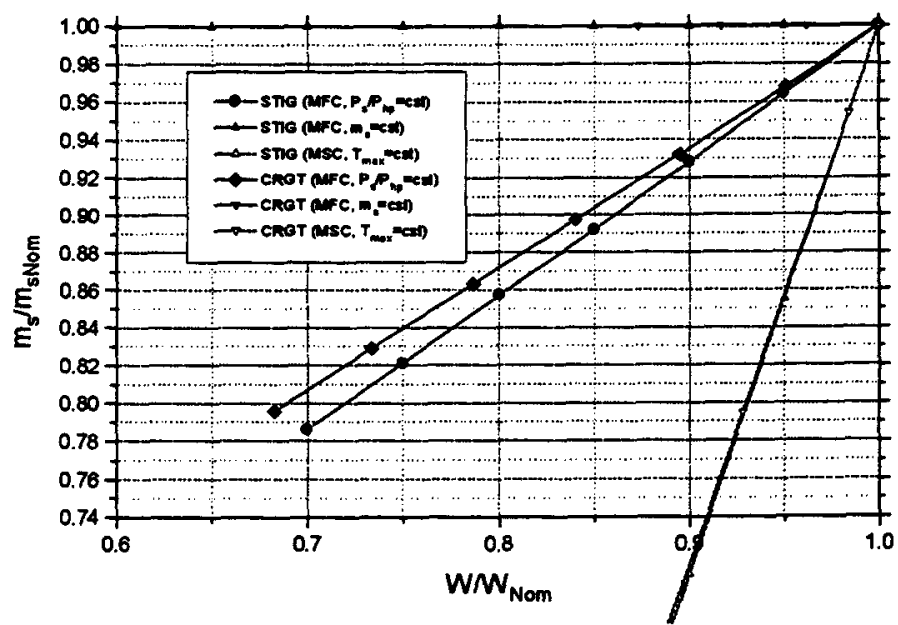

FIGURE 10: Steam Mass Flow Rate vs. Output Power. LM2500 STIG and LM2500 CRGT

topper gas turbine, only two quantities can be changed to obtain a reduction of the load: maximum temperature in the turbine $\left(T_{\max }\right)$, or one of the steam parameters $\left(\mathrm{P}_{\mathrm{s}}\right.$ or $\left.\mathrm{m}_{\mathrm{s}}\right)$. Using steam bleeding, typical of cogeneration plants (Koloseus and Shepherd, 1985), another degree of freedom is available, so in this case three quantities can be changed $\left(\mathrm{T}_{\max }, \mathrm{P}_{\mathrm{s}}, \mathrm{m}_{\mathrm{s}}\right)$. Other possible control systems include variation of turbomachinery geometry (i.e.: Inlet Guide Vane of compressor IGV).

Investigating the case without steam bleeding, imposing a constant steam mass flow rate $\left(\mathrm{m}_{\mathrm{s}}\right)$ and varying the turbine inlet temperature $\left(T_{\max }\right)$, the steam pressure $\left(\mathrm{P}_{s}\right)$ becomes too small for reinjection into the gas turbine, and this power reduction system is thus not feasible. Therefore, the steam pressure $\left(\mathrm{P}_{\mathrm{s}}\right)$ must be fixed, and $T_{\max }$ and steam mass flow rate $\left(m_{s}\right)$ allowed to vary. $T_{\max }$ is determined by the fuel mass flow rate, thus this power reduction system is denoted MFC (Mass Fuel Control). The steam pressure $\left(P_{s}\right)$ must be low in order to obtain the best efficiency, because in this case the steam mass flow rate is highest We conclude that the steam-air pressure ratio $\left(\mathrm{P}_{s} / \mathrm{P}_{\mathrm{hp}}\right)$ should be fixed to the minimum value (i.e. the 


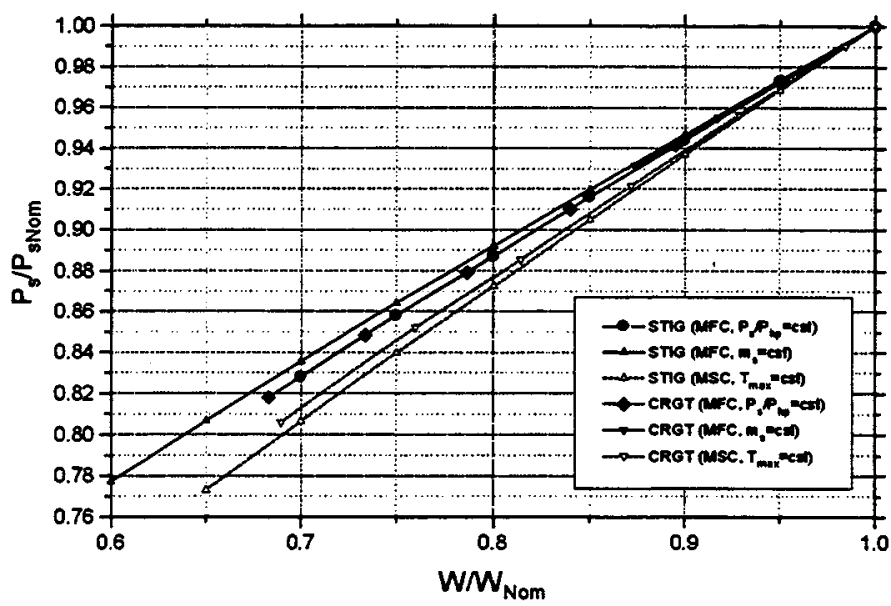

FIGURE 11: Steam Pressure vs. Output Power. LM2500 STIG and LM2500 CRGT

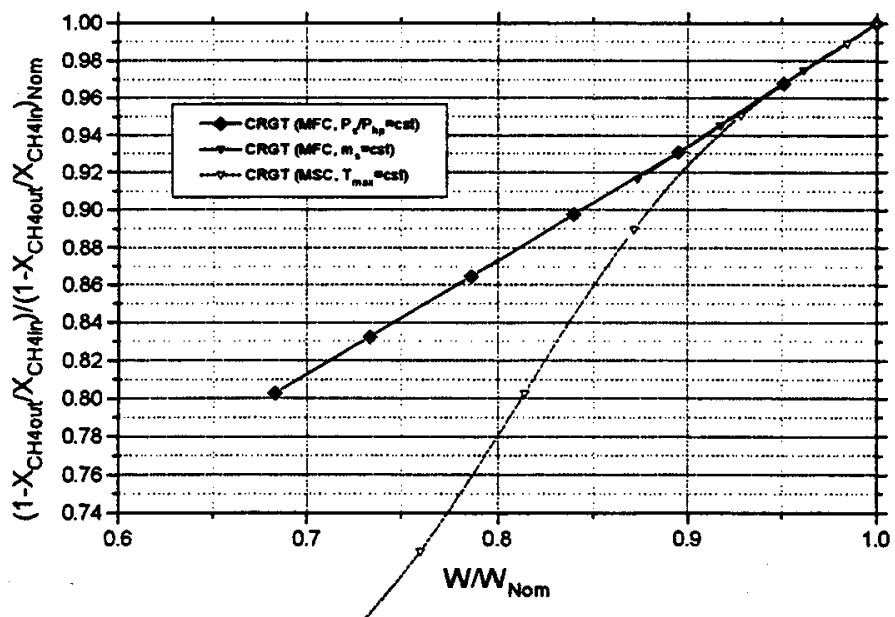

FIGURE 12: Methane Conversion Efficiency vs. Output Power (LM2500 CRGT)

steam pressure must be equal to the compressor air discharge pressure plus all relevant pressure drop in the steam system).

We can furthermore assume that steam produced by the HRSG can be used for cogeneration purposes. A valve is thus necessary to by-pass the steam, and a second degree of freedom is thus introduced. Maintaining the minimum steam-air pressure ratio, the steam mass flow rate is now independent of the turbine inlet temperature $\left(\mathrm{T}_{\max }\right)$. Under nominal load conditions, the HRSG pinch point temperature difference of the simple STIG cycle is very high, enabling a large amount of saturated to be raised and used for cogeneration purposes, provided that the heat recovery evaporator is oversized for nominal load operation. At partial load, the control system with constant steam mass flow rate injected into the gas turbine $\left(m_{s}=c s t\right)$ can be used. However, it should be noted that the global steam flow rate decreases when $T_{\max }$ is decreased, but using the cogeneration utility by-pass valve, the gas turbine steam injection flowrate is maintained constant and the steam mass flow rate for cogeneration is gradually reduced.

Using the cogeneration by-pass valve, maintaining the minimum steam-air pressure ratio, a second control system is possible: Mass

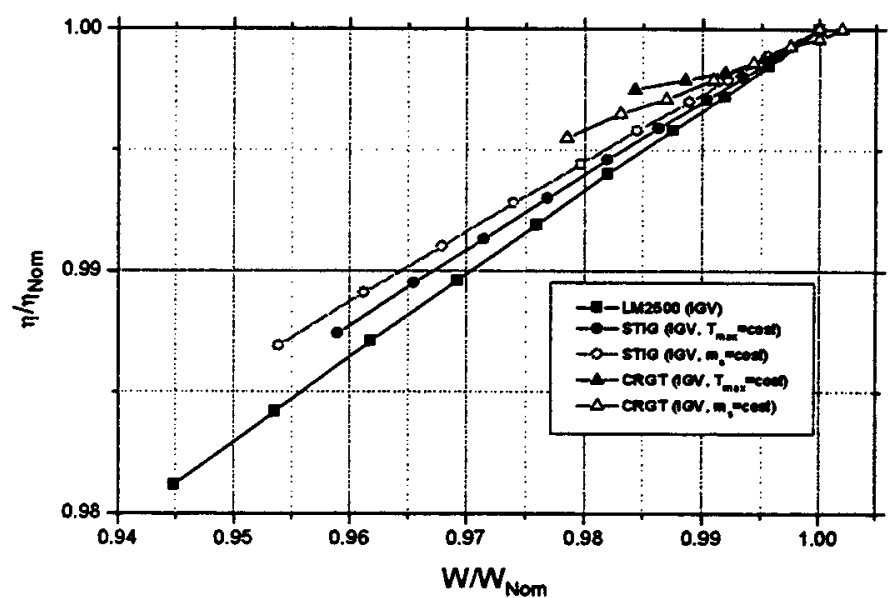

FIGURE 13: Thermodynamic Efficiency vs. Output Power. LM2500, LM2500 STIG and LM2500 CRGT using the IGV Setting

Steam Control (varying the steam mass flow rate injected into gas turbine) coupled fixed turbine inlet temperature (MSC, $\mathrm{T}_{\max }=\mathrm{cst}$ ). This control system does not require over-sizing the HRSG because, at partial load, the steam mass flowrate generated by the heat recovery evaporator decreases a little (due to a decrease of the hot gas mass flow rate at the inlet of the HRSG), whereas the steam mass flow rate injected into the gas turbine decreases strongly. Thus, at partial load, the steam mass flow rate for cogeneration utility increases. This control system (MSC, $\left.T_{\max }=c s t\right)$ is convenient for cogeneration plants where the electric power load usually decreases more than the heat load because more steam is available for cogeneration utility. However, if the electricity load increases more than the heat load, the other control system (MFC, $m_{s}=c s t$ ) is preferable.

For the CRGT cycle, addition of the MSR to the HRSG theoretically adds a further degree of freedom, namely the methanesteam ratio. However, in practice, there is very little degree of freedom for the methane-steam ratio when other operating constraints are accounted for. This is because the methane flowrate is essentially determined by the chosen value for Tmax, and the steam flowrate by either the HRSG operating conditions (if all the steam is reinjected into the gas turbine) or by the cogeneration steam by-pass valve setting. Thus, the methane-steam ratio cannot be varied independently, and the considerations discussed previously for load variation of STIG cycles are also valid for CRGT cycles.

\section{Efficiency}

Figure 7 shows the power/efficiency curves referred to nominal load values. The part load efficiency of the LM2500 Dry using mass fuel control (MFC) decreases because the turbine inlet temperature $\left(T_{\max }\right)$, and consequently the pressure ratio, decrease.

When the HRSG is dimensioned for the nominal STIG steam injection mass flow rate (i.e. without provision for cogeneration utility), imposing $P_{s} / P_{h p}=c s t$, the steam mass flow rate $\left(m_{s}\right)$ and the turbine exhaust temperature decrease using MFC control (figures 10 and 8, respectively). In this case, CRGT and STIG performance are better than Dry cycle performance.

The figures show that part load operation with fixed injection 
steam flow rate (MFC, $m_{s}=c s t$, with over-sized HRSG and progressive reduction of cogeneration steam flowrate) give the best performance for the STIG and CRGT cycles. The efficiency trend of the CRGT cycle is worse than the STIG cycle because the decrease of turbine exhaust temperature (figure 8) is more penalizing for the CRGT cycle. When the cogeneration steam flow is reduced to zero further power reduction is not possible wit this control system. The point at which this limit is reached depends on the minimum allowable pinch point temperature difference in the HRSG. This point is reached faster for the CRGT cycle (figure 7), because the pinch point temperature difference at design conditions is already low. The CRGT cycle presents another limit due to the increase of the molar steam-methane ratio that cannot exceed 6 . However, the pinch point limit is usually reached before the steam/methane ratio limit.

Fixing the turbine inlet temperature and decreasing the steam flow rate injected into the gas turbine (MSC, $\mathrm{T}_{\max }=\mathrm{cst}$ cogeneration steam produced without over-sizing of HRSG), the efficiency trend for both advanced cycles is worse than for the dry cycle. This is a typical cogeneration configuration (high steam mass flow rate, also superheated for cogeneration) and the performance must be evaluated accordingly. In this case the efficiency trend of the CRGT cycle is better than the STIG cycle because in partial load conditions, the exhaust temperature (figure 8) increases. A control limit is present for the CRGT cycle, since decreasing steam mass flow rate, the steammethane ratio cannot drop below 3 , in order to avoid carbon formation in the Methane Steam Reformer.

Comparing the trends of the MSC and MFR control systems, we calculate that decreasing the steam mass flow rate has a pronounced negative impact on efficiency. We may conclude that the improved efficiency of the CRGT compared to the STIG cycle is due mainly to steam injection and to a lesser extent to the chemical heat recovery in the methane-steam reformer.

Finally, although in some cases the STIG efficiency trend at partial load is better than that of the CRGT cycle, comparing absolute values, the CRGT cycle efficiency at $70 \%$ of nominal load is higher than that of the STIG cycle at full load.

\section{Others Parameters}

Figures 8-12 further illustrate the trends described previously. Figure 8 shows the turbine exhaust temperature trend that explains the different relative behavior of CRGT and STIG cycles: a higher exhaust temperature favors CRGT cycle performance because it improves methane conversion in the reforming process. Conversely, a reduction of turbine exhaust temperature is less penalizing for the STIG cycle. A turbine exhaust temperature decrease results from MFC control, while MSC control results in a compression ratio reduction and an exhaust temperature increase, with the turbine inlet temperature kept constant.

The turbine exhaust flowrate of all cycles decreases (figure 9) at part load due to a reduction of the speed of the high pressure shaft. The relative exhaust mass flow rates of STIG and CRGT cycles are very close and they are less than that of the Dry cycle, particularly when only the $\mathrm{m}_{\mathrm{s}}$ reduction (MSC) is used, as confirmed in figure 10 by the steam mass flow rate trend.

The steam pressure (figure 11) decreases at part load for all control systems because the gas turbine compression ratio always decreases in off-design operation. This fact coupled with the fixed ratio between steam and air pressure allows only a limited steam mass flow rate reduction.
An evaluation of the methane conversion efficiency of the CRGT cycle is possible in figure 12 . The decrease is due predominantly on the turbine exhaust temperature decrease, even though the steammethane ratio increases (only a little) and steam pressure decreases. When Mass Steam Control (MSC) is adopted the steam-methane ratio decreases significantly, resulting in a larger methane conversion efficiency decrease.

\section{IGV Setting}

Finally, figure 13 shows the efficiency trend using the IGV (Inlet Guide Vane) control system. Only compressor IGV is used and a linear adjustment is supposed between the first six stator vanes. This control method has a lesser power reduction scope (5-10\% of WNom) but it permits good part load performance, particularly for the STIG cycle, because of the positive effect of compression ratio reduction and of reduced turbine exhaust temperature reduction. This reduces the impact on the reforming process resulting in superior performance for the CRGT cycle.

\section{CONCLUSIONS}

The partial-load performances of CRGT cycle are presented and compared with a standard aeroderivative gas turbine (Dry and STIG version).

The improved performance of the injected cycles is confirmed and similar behavior between STIG and CRGT cycle performance is observed.

The variations of turbine exit temperature and steam/methane ratio are the most important factors for off-design of the reforming process.

The reforming process and the consequent heat recovery increase, impose more severe control limitations for the CRGT cycle, but can also permit interesting integration with a cogeneration process.

\section{ACKNOWLEDGEMENT}

The authors wish to thank LEcole de Mines de Nantes (France).

The authors are also grateful to Prof. E. Carnevale for his support.

The authors would also like to thank MURST

\section{REFERENCES}

Adelman, S.T., Hoffman, M.A., Baughn, J.W., 1995; "A Methane-Steam Reformer for a Basic Chemically Recuperated Gas Turbine", J. of Engineering for Gas Turbines and Power, Jan. 1995, Vol. 117, pp.16-23.

Bettagli, N., Facchini, B., 1995, "Off-Design Performance of Multipressure Heat Recovery Boiler", IGTI Turbo Expo '95, Huston (TX), June 2-6, 1995.

Botros, K.K., de Boer, M.J., Fletcher, H.G., 1997, «Thermodynamic, Environment \& Economic Assessment of CRGT for Exhaust Heat Recovery in Remote Compressor Station Applications», ASME Turbo Expo '97, Orlando (FL), June 2-5, 1997, 97-GT-510.

Carcasci, C., Facchini, B., 1996; "A Numerical Method for Power Plant Simulations", ASME Jnl of Energy Resources Technology, March 1996, vol. 118, pp. 36-43. See also IGTI Turbo Expo '95, Huston (TX), June 2-6, 1995, 95-GT-269. 
Carcasci, C., Facchini, B., Marra, R., 1996; "Modular Approach to Off-Design Gas Turbine Simulation: New Prospects for Reheat Applications", ASME 1996 Turbo-Expo Symposium, Birmingham (UK), June 1996, paper 96-GT-395.

Carcasci, C., Facchini, B., D’Amore, A., 1997a; «Prospettive per 1'Uso del Reforming del Combustibile in turbine a Gas Heavy Duty ad Elevate Prestazioni», $L X$ Convegno Tecnologie e Sistemi Energetici Complessi «S.Stecco», June 26-27, 1997, Milan (Italy), pp.49-63.

Carcasci, C., Facchini, B., Harvey, S., 1997b; «Modular Approach to Analysis of Chemically Recuperated Gas Turbine Cycles", Flowers '97, Florence (Italy), July 1997.

Carcasci, C., Harvey, S., 1998; «Design Issues for the MethaneSteam Reformer of a Chemically Recuperated Gas Turbine Cycle", ASME 1998 Turbo-Expo Symposium, Stockholm (Sweden), June 1998, paper 98-GT.

Cumpsty, N.A., 1989; " Compressor Aerodynamic", Longman Scientific \& Technical, New York.

Davidson, B., Dohner, C., Hay, G., Hollenbacher, R., 1995; "The Intercooled Aeroderivative Gas Turbine - New Technology for a Rapidly Changing Electric Market", CAGT Program Progress Status Report.

Erbes, M.R., Gay, R.R., Cohn, A., 1989; "GATE: A Simulation Code for Analysis of Gas-Turbine Power Plants", ASME Turbo Expo 89, June 4-8, 1989; Toronto, Ontario, Canada.

Facchini, B., 1993; "A Simplified Approach to Off-Design Performance Evaluation of Single Shaft Heavy Duty Gas Turbines", ASME Cogen Turbo '93, Boumemouth, UK, Sept. 1993.

GE Marine \& Industrial Engines, 1992; "LM2500 Gas Turbine», Catalog AE-3232 (12/92).

Koloseus, C., Shepherd, S., 1985; "The Cheng cycle offers flexible cogeneration options". International Power Technology Tech., Rep. March 1985.

Larson, E., Hughes, W., 1996; "Performance Modeling of Aeroderivative Steam-Injected Gas Turbines and Combined Cycles Fueled from Fixed or Fluid-Bed Biomass Gasifiers", ASME 1996 Turbo-Expo Symposium, paper 96-GT-89.

Lloyd, A., 1991; "Thermodynamics of Chemically Recuperated Gas Turbines", MSc Thesis. Center for Energy and Environmental Studies, Princeton University, USA.

Perz, E.W., Riesel, U., Schinagl, H.A., 1995; "A New Approach for Modelling Energy Systems", ASME Cogen-Turbo Power Conference '95, Vienna, Austria, August 23-25, 1995, 95-CTP-82.

Smith, S.S., 1991; "GE Aeroderivative Gas Turbine Performance", GE Turbine Reference Library, GE Power Generation, GER-3572B.

Stewart \& Stevenson, 1992; "STIG Steam-Injected Gas Turbine Generator Sets", Stewart \& Stevenson Service, Inc., Gas Turbine Products Division, ES8185.pm4 5M 10/92. 